\title{
Evaluating a deal in the hospitality industry
}

Received (in revised form): 21 September 2005

\section{Martin Armitstead and Marina Marusic}

are at Cushman \& Wakefield Hotels, a residential and hotel consultancy company.

\begin{abstract}
This article discusses deals between the Owner of the Property and the Operator, and will analyze the issues concerning the evaluation of a deal between those two parties.
\end{abstract}

\section{Keywords:}

deal making, owner, buyer, operator, ROI

Journal of Retail and Leisure Property (2006) 5, 197-203.

doi:10.1057/palgrave.rlp.5100010

A deal is a business transaction upon which two or more parties need to reach an agreement. Deals in the hospitality industry take place every day around the world. Within the industry there are numerous deals. The two most significant one's are:

Deal 1: Between the buyer and the seller.

Deal 2: Between the hotel and/or resort owner/developer (Owner) and the management company (Operator).

The two types of deals are analysed upon the different criteria and each party involved in the negotiation will evaluate different issues prior to concluding contracts. This will be discussed further in the article.

Deals between the buyer and seller can range between small and simple transactions or major takeovers by large companies. The types of deals between the Operator and an Owner are increasingly transacted through a process of competitive tendering. The Owner is often represented by the Hotel Consultancy (the Consultant) who provides the expertise to the Owner of the property development about the management companies. The methodology used by the Consultant will appraise matters different to the basic ones normally discussed between the Owner and the Operator.

Martin Armitstead

Cushman \& Wakefield Hotels Nash House

St George Street London $\mathrm{W}_{1} \mathrm{~S} 2 \mathrm{FQ}$, UK

Tel: $+44(0) 2074919791$

Fax: + 44(0) 2074919793

E-mail: martin.armitstend@eur. cushwake.com

\section{DEAL 1: BETWEEN THE BUYER AND THE SELLER}

During the process of negotiation, the parties involved will analyse the following issues:

The seller

- Why is he selling?

- Is he going to get the best value now or is it better to hold back and to sell later? 
- Where in the market cycle?

- How is he going to sell?

- What professional advice does he need?

- What due diligence information should be prepared?

The buyer

On the other hand, the buyer when assessing the deal will consider the following:

— Is the opportunity in line with the company's strategy?

- Is it opportunistic?

- How much is the deal wanted, and does it justify a premium?

- How could the risks be minimised?

- Are there synergies/economies of scale with the existing business?

- Are there any cost savings?

- Are there contractual issues?

- Is all the information to evaluate the deal available?

- What professional advice is needed?

- Does it provide adequate return?

\section{DEAL 2: BETWEEN THE OWNER AND THE OPERATOR}

In this case, the parties involved are:

- The Owner - often represented by the Consultant. The Consultant provides expertise to the Owner in his choice of the Operator for the Owners individual hotel or resort development (Property).

- The Operator - this could be a hotel management company, but also a spa, golf and marina operator.

In this article, Martin Armitstead and Marina Marusic of Cushman \& Wakefield Hotels, a residential and hotel consultancy, will discuss the Deal 2: Between the Owner of the Property and the Operator, and will analyse the issues concerning the evaluation of a deal between those two parties.

The article will be focusing and will describe the issues that the Consultancy would evaluate on behalf of the client (Owner of the Property) prior to finalising and eventually signing a deal. This will concern analysing all the aspects of the Operator's proposals regarding their management contract, Operator's existing business operations and its dealing with the process of negotiation with the Client. The article looks at the issues that should be considered and analysed prior to proposing any conclusions upon the selection of the Operator.

The Consultancy should weight up the factors enumerated in each of the Operators contract proposals and then present the issues to the Owner with a set of recommendations. These recommendations indicate the advantages and disadvantages of each deal and on what basis further negotiations should take place.

The Consultancy finally examines whether the management company can be considered as a potential and appropriate Operator to a specific project: resort/hotel development fitting with the Owners vision. 
However, for the Consultancy to act on behalf of the Owner, there needs to be an understanding of the Owner's goals and objectives regarding the project development. The Consultant needs to work closely with the Owner and propose solutions to minimise the possible risks, get a fair return on the investment and choose the most suitable Operator or Operators to run the business to ensure future profitability. In this context, it is important that the Consultant can negotiate on behalf of the Owner and request substitute proposals from the Operators in order to assess them.

It needs to be added that no two deals are ever the same. This is because no two projects are the same and no two Owners have the same requirements. Therefore, although there are certain industry standards regarding management contract terms and conditions that serve as an industry benchmark (and upon which management contracts can be compared) often similar management terms offered by the Operator are not necessarily equally favourable to different Owners.

\section{HOW ARE DEALS EVALUATED?}

The basis on which the deal should be evaluated from both sides (Owner's and the Operator's) is by understanding the following issues:

- The value of the Property established by the feasibility study.

- The local and global market trends affecting the hotel/resort development.

- The current and expected market situation on microeconomic and macroeconomic level and how will these affect the project development.

The aim of a deal is to establish the 'best fit' between the two parties and that both parties prosper and are 'winners'. For this to happen, both parties need to be ready to consider compromising on the Terms of the contract, aiming to achieve a 'win-win' situation.

Both parties will be evaluating different issues prior to completion of a deal.

The issues concerning the Owner, which will be analysed in the process of evaluation of a deal, are:

- maximise the return on investment (ROI)

- minimal level of risk

- ways of reducing possible risks

- future expectations for the ROI

- understanding the operation philosophy of the management company

- whether the Operator understands the market where the project is planned to be developed. Is the Operator familiar with the market?

- the location of where hotel/resort will be managed

- hotel company marketing programme, that is, not all hotel companies have good resort/conference expertise

- whether the brand standards are affordable

- the type of a guarantee offered by the management company 
- low base and high incentive fees

- the brand name familiarity in the region and brand's image suitability

- the market perception of the Operator

- the relationship between the Owner and the Operator

- termination of contract on sale.

The issues concerning the Operator when evaluating a deal are:

- length of the contract

- base fees

- any guarantees

- incentive fees

- termination issues

- FF\&E Reserve

- extent of Owner's obligation

- termination clauses and renewal

— whether the development will fit the company's strategy and the existing portfolio

- whether the development will bring economies of scale in the long run

- the relationship between the Operator and the Owner

— impact on other 'brand' hotels

- ability to add brand value.

The purpose of evaluating a deal from the Owner's or Consultancy's point of view is to ensure that the project is a viable opportunity, expected to bring the ROI and eventually contribute to profits.

Some of the following issues that should be looked at by a Consultant and discussed with the Owner prior to selecting an Operator:

- The relationship between the Owner and the Operator.

- Whether the Operator is capable of managing a particular project. In other words, whether they have the adequate skills to manage the services and facilities that the client is planning to develop. It is important to get an understanding of what are the Operator's expertise is. Some are better at city hotels, others have expertise at resort properties that may include spa, golf, rental/fractional, marina, diving and equestrian centre, etc. All of them can offer the Owner different benefits and to the consumer they bring different perceptions of value and standards.

- The implications of the Terms of the Contract. How will these affect the Owner by examining the strengths, weaknesses, opportunities and threats?

The main issues the Owner should be looking for in the evaluation is whether the Operator will bring the value to the project development, and therefore it needs to take into consideration the following four issues prior to selection process:

1. The brand name of the Operator.

2. The deal terms - Terms of Contract. 
3. The enthusiasm from the Operator and the passion shared for the project.

4. The team or teams interaction/relationship between the two parties.

1. The brand name of the Operator: The brand name of the Operator needs to be in line with the Owner's requirements, but also set upon the market research of the area and the feasibility study of the property. Selecting the brand name will depend on the level of exclusivity wanting to be achieved and the image that the Owner wants to pursue for the hotel or resort. The image needs to also be decided upon the market trends and other external factors influencing the area. It is important to evaluate whether the brand fits the following:

- the image of the Property

- the standards of the Property

- the type of the Property development (whether it is a hotel or a resort)

- the current and future local market trends

- the local competition.

Only after understanding the project development specifications and the market environment in which the hotel/resort will be operating and competing can the Consultant pinpoint which type of brand is appropriate. Even so, for the successful project finalisation, the Owner will need to feel comfortable with the Operator. The Owner needs to be clear how important is a particular brand to a particular market and the added value such an Operator will bring to the project and facilities.

For properties to be developed into fractional sales or timeshare, the optimum brand fit is essential in order to maximise residential sales. Therefore, decision regarding the brand name of the development will also depend upon the decision regarding residential units.

2. The deal terms - Terms of Management Contract: There are a few very important issues that need to be analysed when receiving the contract proposals. These are the following:

- the fees: the Base fee, the Incentive fee, Sales and Marketing fees, etc

- the level of risk ratio between the client and the Operator

- the guarantee (if any)

- the legal factors

- the termination and renewal

— the Owner's rights.

The price, in other words the fees charged by the Operator and the guarantee are two of the issues to be evaluated from the proposed contract. This is because the price needs to be in line with expected returns. Management Contract terms usually include a Base fee of around $3 \%$ of Gross Revenue and an Incentive fee of around 10\% of Gross Operating Profit. Other fees such as Sales and Marketing are normally between 1 and 3\%. In addition, charges for Operators reservations and direct bookings need to be added and evaluated. 
Taking into consideration all of the above, the Owner should be evaluating a deal according to the guarantee offered by the Operator. Any operator offering a proposal including a guarantee would most probably mean that he has substantial interest in either the destination or he believes in the success of the project and would not like it to go to any of his competitors.

The termination of the contract is another issue within the Management Contract terms, which needs to be evaluated prior to concluding a deal. The industry standard for the termination is usually for up to approximately 20 years. The Owner needs to ensure that if it comes to a termination of a contract on the part of the Operator, the Operator is required to pay the cancellation fee to the Owner of the Property.

Another issue that the Owner should look at is whether in the case of Operator's underperformance, when the hotel does not achieve a threshold level of bottom line profitability, the Owner has a right to withdraw the contract.

3. The enthusiasm: This concerns the level of Operator's interest towards the project development and enthusiasm of managing a hotel or a resort. The level of enthusiasm is a very important issue that needs to be taken into consideration by the Owner or a Consultancy as the level of interest and passion for the project from the Operator's point of view will reflect the success of future business. The high level of enthusiasm coming from the Operator will effectively secure better cooperation between the two parties in the future.

The level of enthusiasm is demonstrated through the Operator's willingness of compromising on the following issues:

- Lowering fees or agreeing on more favourable fees to the owner, which could work fine for both of the parties.

- Offering a type of guarantee: Accepting to share more risk with the owner, or having an equal amount of risk as the Owner (50/50).

- Cooperation with the Owner.

- Technical input.

The interest towards the project in turn affects the relationship between the two parties. High interest towards the project secures strong relationship between parties. Both parties need to be equally excited about the project in order to run the project successfully. If the Operator is equally enthusiastic about the project, he will be more open towards the risk taking and sharing the risks with the Owner. If the Operator is willing and agreeing on sharing the risks, this will boost the Owner's confidence in proceeding with that particular Operator.

4. The team or teams interaction: This concerns the relationship between the Owner and the Operator. The synergy between the two parties and the strength of the relationship is crucial for the successful business. Therefore, it is very important to determine the level of relationship prior to signing a deal, and establish whether the two could work together in the future towards achieving the same goals. 
Not having the same views towards the objectives could create difficulties in engaging into the same project, as this will naturally clash with one or the other party's views.

Equally, it is important that parties share the passion for the project and have the same mentality and the way of thinking. To be able to establish and continue a good relationship, both parties need to be prepared to compromise on certain issues and find the medium that could work for both, where both parties can be winners. 